\title{
Analytic Study Of The Trend Of Ghana's GDP Before And After Re-basing
}

\author{
Adu-Manu Kofi Sarpong, Valley View University, Accra, Ghana \\ Abraham Bamfo Boakye, Valley View University, Accra, Ghana \\ Abraham Amponsah, Valley View University, Accra, Ghana \\ Clement Yeboah, Strayer University, Columbus Ohio Campus, USA
}

\begin{abstract}
The fourth republican constitution came into force in 1993. Ghana statistical Service also rebased Ghana's GDP in the same year. From 1993 to 2005, the average GDP growth rate was about 4.3\%. Within the period of 1993 and 2005, Ghana was still below the lower middle income level. Another re-basing took place in 2006. It is now believed that we are in the lower middle income level. The study was conducted to develop mathematical models to predict the trend of Ghana's GDP before re-basing and after re-basing in 2006, use the models before and after rebasing to predict the future trend in Ghana's GDP growth, compare our GDP growth before rebasing and after re-basing, to determine whether or not, there are fluctuations in our GDP growth and predict Ghana's per capita income status in 2015. Data on Ghana's GDP were collected from the Statistical Service Department. The GDP figures from 1993-1995 and from 1996-2010 were plotted separately on graphs. A function whose graph best fits each trend was found using regression analysis. It was observed that Ghana's GDP trends before and after re-basing was exponential. There were also no fluctuations in the growth of the economy. Ghana may still be in the lower middle income status by 2015.
\end{abstract}

Keywords: Ghana's GDP; Re-basing in Ghana; Economic Growth in Ghana

\section{INTRODUCTION}

\section{GHANA'S GDP FROM 1993-2005}

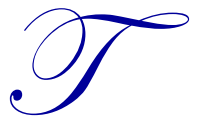

he fourth republican constitution came into force in 1993. Ghana statistical Service also re-based Ghana's GDP in the same year. From 1993 to 2005, the average GDP growth rate was about 4.3\%. Within the period of 1993 and 2005, Ghana was still below the lower middle income level. Another re-basing took effect from 2006. It is now believed that we are now in the lower middle income level.

\section{OBJECTIVES}

- $\quad$ To develop mathematical models to predict the trend of Ghana's GDP before re-basing and after re-basing in 2006.

- Use the models before and after re-basing to predict the future trend in Ghana's GDP growth.

- $\quad$ Compare our GDP growth before re-basing and after re-basing.

- $\quad$ Determine whether or not, there are fluctuations in our GDP growth.

- $\quad$ To predict Ghana's per capita income status in 2015.

\section{REASONS FOR RE-BASING IN 2006}

The Ghana Statistical Service completed its work on rebasing of the national accounts estimates in November 2010. Re-basing was done with respect to the following reasons: 
- $\quad$ The use of 1993 Systems of National Accounts instead of the 1968 edition.

- Improvement and revision of data sources and

- Updating of classification by adapting the latest version of the International Standard Industrial Classification (ISIC) revision 4(Ghana National Statistical Service News brief,2010 p 1)

To the Ghana National Statistical Service News Brief (2010)," the measures for rebasing our GDP in year 2006 have led to changes in the size of Ghana's GDP, growth rates, and sectoral contributions and all related indicators that use GDP"(p 1). To the News Brief (2010) again, "the most significant features of the rebased series are a $60.3 \%$ increase in the size of the GDP in the base year 2006, and the Services sector being the largest contributor to the GDP"(p 1).

The purpose of this paper is to explain mathematically, the trend of Ghana's GDP growth before re-basing and after re-basing, and to compare the trend of GDP at 1993 constant prices with 2006 constant prices.

Ghana has now attained the lower middle income status. The problem is what is the growth of the GDP in mathematical terms?

The objectives of this study are: to develop mathematical models to predict the trend of Ghana's GDP before re-basing and after re-basing in 2006, use the models before and after re-basing to predict the future trend in Ghana's GDP growth, compare our GDP growth before re-basing and after re-basing, determine whether or not, there are fluctuations in our GDP growth and to predict Ghana's per capita income status in 2015.

\section{A BRIEF OVERVIEW OF GHANA'S ECONOMY}

"Ghana is well endowed with natural resources and agriculture accounts for roughly one-third of GDP and employs more than half of the workforce, mainly small landholders. The services sector accounts for $40 \%$ of GDP" (Ghana Economy Profile, 2012). To the Ghana National Statistical Service News Brief (2010)," the service sector accounts for the largest contributor of Ghana's GDP from year 2006 to 2010 with about $50 \%$ of GDP at basic prices. This is followed by Agriculture sector and the industrial sector being the least contributor". "Gold, cocoa production and individual remittances are major sources of foreign exchange. Crude oil production in Ghana began in the midDecember, 2010, and is expected boost our economic growth" (Ghana Economic Profile, 2012 p 1).

\section{REPORT ON STUDIES CONDUCTED ON GDPS}

Hoffmann et al (2005) used regression models to study the trends of GDP growth in China from 19962001. The trend gave rise to linear model. They could not determine whether or not, there were fluctuations in the trend.

Kyeremeh, (as cited in The Economy of Ghana, 2008) used vector autoregressive (VAR) models to study the effects of exchange-rate volatility \& macroeconomic changes on economic growth in Ghana. The variables he used were cedi per dollar, exchange rate, Ghana's money supply, price level, per person real output, and Ghana's interest rate. His conclusions were that impulse responses suggest significantly dynamic interrelationship between the exchange rate and inflation. While inflation leads to the weakening of the cedi, a declining cedi in part may cause inflation. His co-integration test suggested the following:

- $\quad$ A significant long-run relationship between the real output growth and the exchange rate;

- $\quad$ A significant long-run relationship between price inflation and exchange rate; and

- $\quad$ An insignificant long-run relationship between the real interest rate and exchange rate.

Autoregressive models cannot the clue as to whether there are fluctuations in economic trends.

In the Current State of the Macro Economy of Ghana, (2000 -2009), the Centre for Policy Analysis (CEPA) discusses the inflation trend, budget deficits, Government Domestic Revenues and Expenditures and Money Supply Growth with charts. The center could not use any mathematical models to explain the trends. The charts also could not tell whether there were fluctuations in the growth of the Economy. 
Quartey and Blankson (as cited in The Economy of Ghana, 2008) investigated hosehold savings in Ghana. They used both classical linear regression technique and a logistic regression approach to compare the policy effects on savings under the two separate models. Their results were that higher levels of education (tertiary) would significantly increase the probability of savings in 1991/92 but cannot be said for 1998/9; the probability of savings increases as one attains tertiary education, but the marginal effect was not significant. Also, the probability of savings is also dependent on the type accommodation the household has; households living in rented or rent-free accommodation are likely to save more than more than those living in their own houses. Moreover, the marginal effects increased over two periods. They concluded that households living in rented accommodation are more likely to have financial savings perhaps to pay for rent advance or to put up their own houses than those living in their own hoses. Those living in their own houses may have used their savings to put up houses - a form of savings, particularly in a country where real interest rates are low and sometimes negative. However there are some limitations of using regression models. Ajay and Alka (2003) cited specific limited range, cause and effect, and using past trends to estimate future trends as some of the limitations.

\section{METHODOLOGY}

The study is focused on describing Ghana's GDP using mathematical models. The research is therefore descriptive.It describes the relationships, association or correlation between time in years from 1993 to 1995 and their respective total GDPs and from 1996 to 2010 and their respective total GDPs. In prediction Ghana's total GDP in 2015, the study describes the estimated GDP levels before and after rebasing by 2015. Quantitative data which comprises Ghana real GDP figures from 1993-2010 were used to describe the relationship between time and GDP figures from 1993 to 2005 i.e. before rebasing and from 2996 to 2010 i.e. after rebasing. Based on the research framework, mathematical models were developed showing first the correlation between time and total GDP. Other statistical parameters relating to measures of association which are coefficient of determination, standard error and the rate of change of total GDP with respect to time were calculated for the period and interpreted.

The data are secondary data compiled by Ghana Statistical Service. Ghana's GDP data from 1993-2005and from 2006-2010 were plotted separately on graphs. A function whose graph best fits each trend was found using regression analysis. Chukwus's Model was also used to determine whether or not, there were fluctuations in the trends of Ghana' GDPs.

\section{DATA ANALYSIS, PRESENTATION AND DISCUSSION}

\section{The Trend of Ghana's Gross Domestic Product from 1993 to 2006}

The trends of Ghana's GDP from 1993 to 2004 are as shown below. 


\section{Ghana's Real GDPs from 1993- 2005}
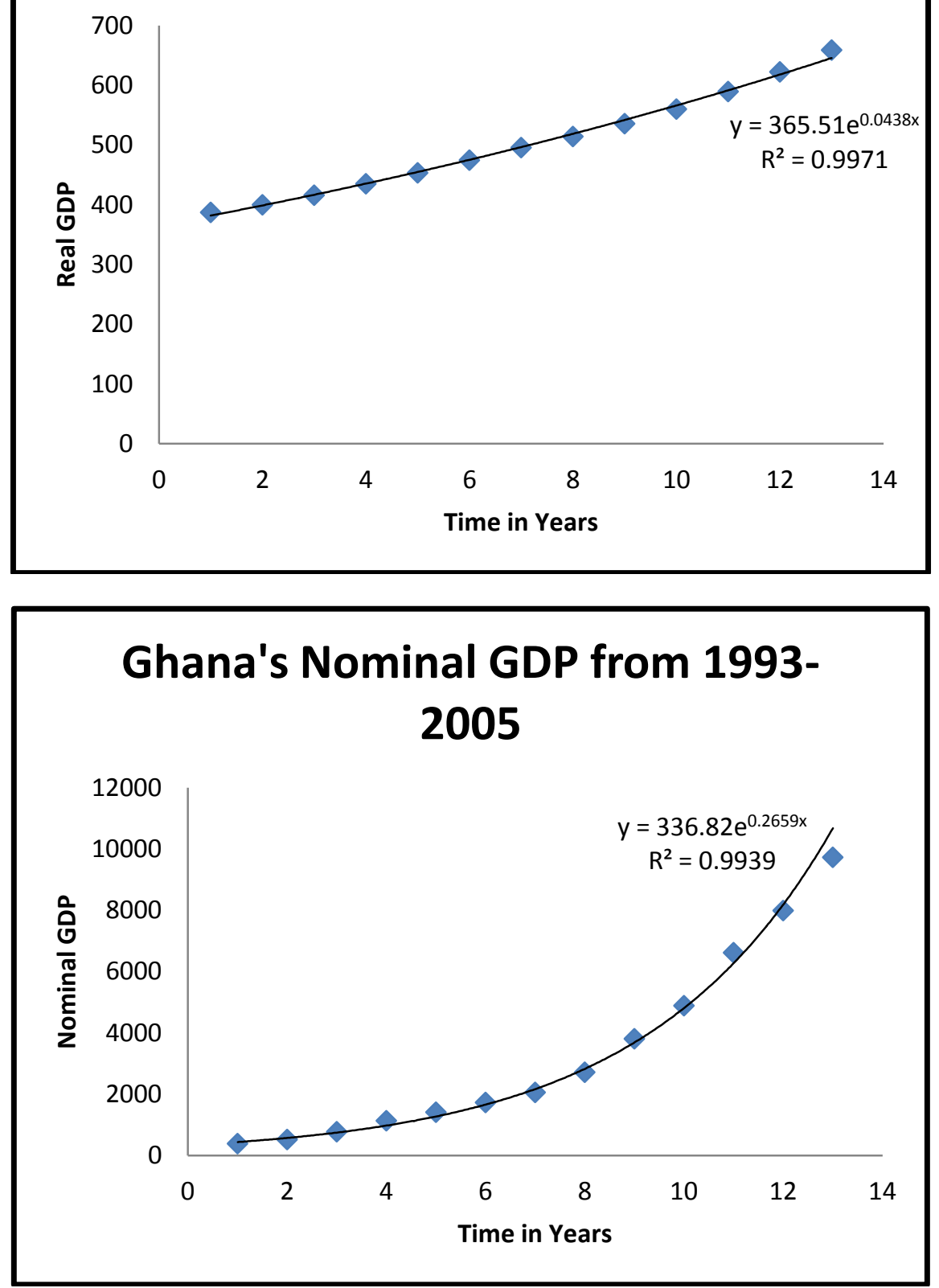

It is observed here that both the real and nominal GDPs have been growing progressively, however, between 1993 and year 2000, there were some fluctuations in terms of percentage real GDP but from year 2000 to year 2006, but GDP growth rate in terms of percentage has been generally increasing.

The graphs of both real and nominal GDPs against time are assumed to obey exponential growth model. The equations of the models for real and nominal GDPs are respectively 
$Y(t)=365.51 e^{0.044 t}, t \geq 1$

And

$Y(t)=336.819 e^{0.266 t}, t \geq 1$
1

2

\section{INVESTIGATING GHANA'S REAL GDP USING CHUKWU'S MODEL} is given by

The model developed by Chukwu (1993), which describes the dynamics of the growth of wealth of nations

$\dot{Y}-a_{-1} \dot{Y}(t-h)=-a_{0} Y(t)+a_{1} Y(t-h)+p(t)+q(t)$

Where $Y(t)$ is the GDP at time $t>0$.

The values of $a_{-1}, a_{0}$, and $a_{1}$ can be estimated by using matrix algebra under the following assumptions:

That $p(t)+q(t)=0$ for all $t>0$;

The equation

$\dot{Y}-a_{-1} \dot{Y}(t-h)=-a_{0} Y(t)+a_{1} Y(t-h)$

Be converted to difference equation, that is,

$Y_{t}-Y_{t-1}-a_{1}\left(Y_{(t-h)}-Y_{t-(h+1)}\right)=-a_{0} Y_{t-1}+a_{1} Y_{t-(h+1)}$

The real number, $h=\frac{108}{487}$ according to Ghana Data Profile (2007);

That $\dot{Y}(t-h)$ and $Y(t-h)$ be obtained by multiplying $\dot{Y}(t)$ and $Y(t)$ by $\left(1-\frac{108}{487}\right)$.

It has been pointed out by Chukwu (1993), that if

$p(t)+q(t)=0$ for all $t>0 ;$

$a_{-1}, a_{0}$ and $-a_{1}$ are nonnegative real numbers such that $a_{-1} \leq 1$;

$a_{-1}\left(a_{0}-2 a_{1}\right)-a_{1}>\frac{1}{e h}$.

Then every solution of oscillates. The table below shows the values of $Y_{t}-Y_{t-1}, Y_{t-h}-Y_{t-(h+1)}, Y_{t}$ and $Y_{t-h}$ from 1993 to 2005. 
We let the values of $\left(Y_{t}-Y_{t-1}\right)=T$ be solution vector and the values of $\left(Y_{t-h}-Y_{t-(h+1)}, Y_{t} Y_{t-h}\right)=X$ be coefficient matrix. The systems of equations are as shown below:

$$
\begin{aligned}
& 9.85244 a_{-1}-387.250 a_{0}+301.3711 a_{1}=12.660 \\
& 12.52179 a_{-1}-399.910 a_{0}+311.2236 a_{1}=16.090 \\
& 14.87984 a_{-1}-416.000 a_{0}+323.7454 a_{1}=19.120 \\
& 14.21600 a_{-1}-435.120 a_{0}+338.6252 a_{1}=18.267 \\
& 16.56160 a_{-1}-453.387 a_{0}+352.8412 a_{1}=21.281 \\
& 16.35926 a_{-1}-474.668 a_{0}+369.4028 a_{1}=21.021 \\
& 14.41290 a_{-1}-495.689 a_{0}+385.7621 a_{1}=18.520 \\
& 16.73592 a_{-1}-514.209 a_{0}+400.1750 a_{1}=21.505 \\
& 18.96245 a_{-1}-535.714 a_{0}+416.9109 a_{1}=24.366 \\
& 22.87463 a_{-1}-560.080 a_{0}+435.8733 a_{1}=29.393 \\
& 22.58786 a_{-1}-589.473 a_{0}+458.7480 a_{1}=32.789
\end{aligned}
$$

The coefficient matrix and the solution vector are as shown below:

$X=\left(\begin{array}{lll}9.85244 & -387.250 & 301.3711 \\ 12.52179 & -399.910 & 3112.236 \\ 14.87984 & -416.000 & 323.7454 \\ 14.21600 & -435.120 & 338.6252 \\ 16.56160 & -453.387 & 352.8412 \\ 16.35926 & -474.668 & 369.4028 \\ 14.4129 & -495.689 & 385.7621 \\ 16.73592 & -514.209 & 400.1750 \\ 18.96245 & -535.714 & 416.9109 \\ 22.87463 & -560.080 & 435.8733 \\ 22.58756 & -589.473 & 458.7480\end{array}\right) T=\left(\begin{array}{l}12.660 \\ 16.090 \\ 19.120 \\ 18.267 \\ 21.281 \\ 21.021 \\ 18.520 \\ 21.505 \\ 24.366 \\ 29.393 \\ 32.879\end{array}\right)$

The values of $a_{-1}, a_{0}$ and $a_{1}$ can be found using the formula

$$
\begin{aligned}
& \left(\begin{array}{l}
a_{-1} \\
a_{0} \\
a_{1}
\end{array}\right)=\left(X^{T} * X\right)^{-1} * X^{T} * T \\
& \left(X^{T} * X\right)=\left(\begin{array}{lll}
324465.1266 & -9027598.288 & 7025584.705 \\
-9027598.288 & 256142146.1 & -199338549 \\
7025584.705 & -199338549 & 155132053.6
\end{array}\right)
\end{aligned}
$$

And 


$$
\begin{aligned}
& \left(X^{T} * X\right)^{-1}=\left(\begin{array}{lll}
0.00015893 & 2.27081 \mathrm{E}-06 & -4.37547 \mathrm{E}-06 \\
2.19108 \mathrm{E}-06 & 7949320.348 & 10214562.03 \\
-4.38215 \mathrm{E}-06 & 10214562.03 & 13125307.94
\end{array}\right)
\end{aligned}
$$

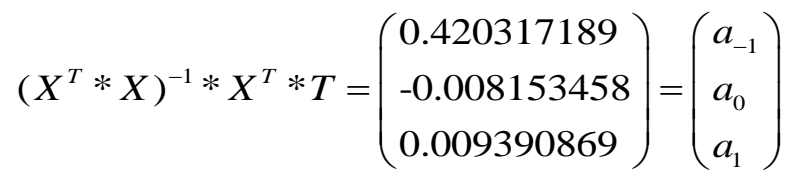

To Chukwu (1993), for every solution of (3 p.5) to oscillate, the values of $a_{-1}, a_{0}$ and $-a_{1}$ should be nonnegative real numbers such that $\left|a_{-1}\right| \leq 1$. We note that the values of $a_{0}$ and $-a_{1}$ are negative real numbers and this contradicts Chukwu's conditions. Hence every solution of (3. P.5) will not oscillate. Another condition for oscillation is that

$a_{-1}\left(a_{0}-2 a_{1}\right)-a_{1}>\frac{1}{e h}$

Now,

$$
\begin{aligned}
a_{-1}\left(a_{0}-2 a_{1}\right)-a_{1} & =0.420317189(-0.008153458-2(0.009390869))-0.009390869 \\
& =-0.020712185<\frac{1}{\mathrm{eh}}=1.65883766
\end{aligned}
$$

Hence no oscillation occurs in every solution of

$\dot{Y}-a_{-1} \dot{Y}(t-h)=-a_{0} Y(t)+a_{1} Y(t-h)$

Results of computation from 2006 to 2010 (2006 Rebasing)

$$
\begin{aligned}
& a_{-1}=0.80065 \\
& a_{0}=0.02565 \\
& a_{-1}=0.03127 \\
& a_{-1}\left(a_{0}-2 a_{1}\right)-a_{1}=0.80065(0.02565-2(0.0312))-0.0312 \\
& =-0.06081<\frac{1}{\mathrm{eh}}=1.65884
\end{aligned}
$$

To conclude, there are no oscillations in the trend of Ghana's real GDP from 1993 to 2005 and 2006 to 2010.

\section{DISCUSSIONS}

As pointed out by Chukwu (1993), the equation which describes the dynamics of the growth of wealth of nations is given by

$$
\dot{Y}-a_{-1} \dot{Y}(t-h)=-a_{0} Y(t)+a_{1} Y(t-h)+p(t)+q(t)
$$


This model tells us whether or not every solution of this equation will oscillate or fluctuate.

From the analysis of Ghana's real GDP from 1993 to 2005 and from 2006 to 2010 using Chukwu's model, the values of $a_{-1}, a_{0}$, and $a_{1}$ are respectively $0.420317189,-0.008153458$, and 0.009390869 for 19932005 and $0.80065,0.02565$ and 0.03127 . The values of $a_{-1}\left(a_{0}-2 a_{1}\right)-a$ before and after rebasing do not satisfy Chukwu's conditions for oscillation. So there are no oscillations or fluctuations in the trend of Ghana's real GDP from 1993 to 2004.

The fact that there are no oscillations or fluctuations in the economy does not mean that everything is well with our economy. To the African Peer Review Mechanism (2005), the economy of Ghana remains relatively weak however; it is highly vulnerable to external shocks from the world economy and from sub-regional political instability due to factors originating in neighboring countries.

\section{COMPARING GDPs AT 1993 AND 2006 CONSTANT PRICES}

The table below shows the real GDPs before and after rebasing.

\begin{tabular}{|c|c|c|c|}
\hline Year & $\begin{array}{c}\text { Actual Real GDP At 2006 Constant } \\
\text { Prices In Ghc Million }\end{array}$ & $\begin{array}{c}\text { Predicted GDP At 1993 Constant } \\
\text { Prices In Ghc Million }\end{array}$ & $\begin{array}{c}\text { Predicted GDP At 2006 Constant } \\
\text { Prices In Ghc Million }\end{array}$ \\
\hline 2006 & 18,705 & 7212.2 & 18749 \\
\hline 2007 & 19913 & 7924.6 & 19976 \\
\hline 2008 & 21592 & 8836.5 & 21283 \\
\hline 2009 & 22454 & 9994.1 & 22676 \\
\hline 2010 & 24187 & 11449.0 & 24161 \\
\hline
\end{tabular}

It is observed from the table that the predicted GDPs at 1993 constant prices are much lower than their respective GDPs at 2006 constant prices. The 2006 constant prices indicate that we are now in the lower middle income.

\section{PREDICTION}

- $\quad$ Using 1993 constant prices, the GDP of Ghana is expected to reach GHC 29,879 million in 2015.

- If 2006 constant prices is used, the GDP of Ghana is expected to reach GHC 33,173 million in 2015

- If 1968 accounting system is used, Ghana's nominal GDP will reach GHC 41427 million in 2015.

- If 1993 accounting system is used, Ghana's nominal GDP will reach GHC 143,979 million in 2015.

\section{CONDITIONS FOR MIDDLE INCOME}

Per capita income should be in the range of 3976-12,275 dollars, and lower middle income range should be 1006-3975 dollars.

\section{EXPECTED GHANA'S PER CAPITA INCOME IN 2015}

- $\quad$ By calculation, per capita income using 1993 rebasing is expected to be 1023.30 dollars by 2015

- $\quad$ Per capita income using 2006 rebasing is expected to be 3556.47 dollars by 2015.

- $\quad$ Ghana will still be at the lower income level by 2015.

\section{RECOMMENDATIONS}

- To attain the middle income status by 2015 , our GDP growth rate should be higher than the $6 \%$ in the model.

- Ghana's economic activities in terms of export should increase. 


\section{AUTHOR INFORMATION}

Abraham Bamfo Boakye, Valley View University, Accra, Ghana. E-mail: Abrahambb2005@yahoo.com

Abraham Amponsah, Valley View University, Accra, Ghana. E-mail: Abramponsah@yahoo.com

Adu-Manu Kofi Sarpong, Valley View University, Accra, Ghana. E-mail: ksarpsnr@yahoo.co.uk; kamsarpong@vvu.edu.gh

Clement Yeboah, Strayer University Columbus Ohio Campus, USA. E-mail: clejos200@yahoo.co.uk (Corresponding author)

\section{REFERENCES}

1. Ajay,G. and Alka, G. (2003) Mathematics and Statistics for CA Professional Examination-I/B.Com. Third Edition. Taxmann Allied Services Pvt. Ltd. 59/32, New Rohtak Road, New Delhi-11005 India. 677

2. Centre for Policy Analysis (2009) The Current State of the Macro Economy of Ghana. (2000-2009). 14-26. Retrieved July 12, 2012 from http://www.cepa.org.gh/publications/The Current State of the Macro Economy of Ghana 2000-200981.pdf

3. Chukwu, E.N. (1993). Mathematical Controllability Theory of the Growth of Wealth of Nations. Department of Mathematics, North Caroline State University, Raleigh, NC 27695-8205, USA; 87-90

4. Ghana Economy profile. (2012), Retrieved July 12, 2012, from http://www.indexmundi.com/ghana/economy_profile.html

5. Ghana Statistical Service News Brief. (2010). New Series of the Gross Domestic Product (GDP) Estimates, Retrieved November 20, 2011, from http://www.statsghana.gov.gh//.../gdp_newsletter_rebased_nov_2010

6. Hoffmann, L. D., Bradley G. L. and Rosen H. K. (2005). Applied Calculus for Business, Economics and Social and Life Sciences. McGraw-Hill Companies, Inc., 1211 Avenue of Americas, New York, NY, 10020; 282, 295, 543, 602

7. The Economy of Ghana (2008). An Analytical Perspectives on Stability, Growth \& Poverty. James Currey Woeli Publishing Services. 97-98, 162-167 
NOTES 